\title{
Las tres vidas de Altamira y el futuro
}

\section{The three lifes of Altamira and the future}

\author{
DAVID BARREIRO \\ Instituto de Ciencias del Patrimonio (Incipit), CSIC \\ http://orcid.org/0000-0001-9963-1555 \\ david.barreiro@incipit.csic.es \\ FELIPE CRIADO-BOADO \\ Instituto de Ciencias del Patrimonio (Incipit), CSIC \\ http://orcid.org/0000-0003-4235-706X \\ felipe.criado-boado@incipit.csic.es
}

\section{VIRTUDES TÉLLEZ}

Facultad de Ciencias Sociales de Talavera de la Reina

(Universidad de Castilla-La Mancha)

http://orcid.org/0000-0002-7293-6946

virtudes.tellez@uclm.es

CRISTINA SÁNCHEZ-CARRETERO

Instituto de Ciencias del Patrimonio (Incipit), CSIC

http://orcid.org/000-0002-3900-3976

cristina.sanchez-carretero@incipit.csic.es

EVA PARGA-DANS

Grupo de Estudios Territoriales, Facultad de Sociología,

Universidad de A Coruña

http://orcid.org/0000-0002-0095-2963

eva.parga.dans@udc.es

RAQUEL SÁNCHEZ-MARTÍN

raquel.sanchez-martin@incipit.csic.es 


\title{
A la memoria de José Antonio Lasheras
}

\section{RESUMEN}

Entre los años 2012 y 2014 el Incipit (Instituto de Ciencias del Patrimonio, del CSIC) realizó un estudio del Valor Social de Altamira, en el marco del Programa de Investigación para la Conservación Preventiva y Régimen de Acceso de la Cueva de Altamira, promovido por el Ministerio de Educación, Cultura y Deporte, y dirigido por Gaël de Guichen (ICCROM). A partir de esta investigación obtuvimos un conjunto de datos que nos permiten plantear algunas ideas para una gestión alternativa de un sitio patrimonial en riesgo, lo que pretendemos concretar en el presente texto. El argumento principal es que la patrimonialización de un sitio como éste introduce al sitio en unas condiciones totalmente distintas que generan nuevas posibilidades y riesgos. Nuestra propuesta es que sólo desde la aceptación de que el sitio alcanza un nuevo régimen de existencia que poco tiene ya que ver con el anterior se puede plantear un modelo adecuado de gestión y protección del sitio. Pretendemos asimismo argumentar que ese modelo (al que denominaremos "cuarta vida") se tiene que basar en la realización de estudios prospectivos de los nuevos riesgos y su gestión. Es decir, que se deben renovar las evaluaciones de riesgos para recoger no sólo los efectos que tiene el uso social de los sitios sobre su conservación, sino también a la inversa: los efectos sociales de dicha conservación.

Palabras clave: Altamira. Patrimonialización. Valor social. Evaluación de riesgos.

\begin{abstract}
Between 2012 and 2014 the Incipit (Institute of Heritage Sciences), part of the Spanish National Research Council (CSIC), carried out a study entitled 'The Social Value of Altamira' as part of the Research Programme for the Preventive Conservation and Access Regime for the Cave of Altamira, promoted by the Spanish Ministry of Education, Culture and Sport and directed by Gaël de Guichen (ICCROM). This research provided us with a set of data which has made it possible for us to propose certain ideas for an alternative model of management for at-risk heritage sites. These ideas shall be presented in this text. Our main line of argument is that the heritagization of a site such as Altamira is accompanied by totally different conditions to those which existed beforehand, leading to new possibilities and risks. Our proposal is that only by accepting that the site will have a new type of existence (a "third life"), which has little to do with its previous stages can a suitable model of management and protection of the site be formulated. Furthermore, we aim to prove that this model must be based on prospective studies of the new risks and the management thereof. In other words, the assessments of the risks must be renewed in order to include not only the effects of the social use of the sites on their conservation but also the contrary: the social effects of the conservation itself.
\end{abstract}

Keywords: Altamira. Heritagization. Social value. Risk assessment.

\section{INTRODUCCIÓN}

En este texto vamos a plantear algunas ideas para viabilizar una gestión alternativa de sitios patrimoniales en riesgo, particularmente aquellos que son puestos en valor y devienen producto turístico y, entre éstos, aquellos que son Patrimonio de la Humanidad. La declaración de patrimonio mundial produce condiciones de existencia totalmente nuevas 
para esos sitios. Sólo a partir del reconocimiento de esto se puede proponer un adecuado modelo de gestión de esos sitios para el futuro.

Nos basaremos en los resultados del Proyecto Valor Social de Altamira, liderado por el Incipit y realizado en el marco del Programa de Investigación para la Conservación Preventiva y Régimen de Acceso de la Cueva de Altamira (en adelante, Programa), que se desarrolló entre 2012 y 2014, promovido por el Ministerio de Educación, Cultura y Deporte, y bajo la dirección científica de Gaël de Guichen (ICCROM).

Como parte de este programa, el Incipit desarrolló un estudio del Valor Social de Altamira, orientado a caracterizar Altamira como fenómeno social, en diferentes dimensiones y a diferentes escalas, a fin de evaluar mejor la trascendencia y relevancia de las decisiones que habría que tomar. Los resultados de esta investigación alimentan la reflexión contenida en este texto. Pueden consultarse en detalle en la Colección Proyecto Valor Social de Altamira, disponible en el repositorio institucional en abierto Digital. CSIC (https://digital.csic.es/handle/10261/112860), una síntesis del mismo en Barreiro y Criado-Boado 2015, y un estudio focalizado en la relevancia económica en Parga-Dans y Alonso 2017.

Como puntualización de interés, hay que recordar que la sede del Incipit está en Santiago de Compostela, otra ciudad reconocida como Patrimonio de la Humanidad, que constituye un destino turístico, cultural, religioso de primer orden y que ha asentado una imagen de marca, al menos un nombre, bien conocido mundialmente en la actualidad. Las transformaciones de Santiago de Compostela desde la declaración de la UNESCO de 1993, y desde la celebración del Año Santo Xacobeo de ese año, primer año santo de la época política que representó Fraga Iribarne y, en realidad, de la era postmoderna, son bien reconocibles y representan un caso de estudio y un estímulo para cavilar sobre las transformaciones presentes y futuras de los sitios patrimoniales y la tradición.

En el caso que presentamos, no obstante, nos centraremos en nuestra experiencia en Altamira, que nos ha permitido plantear un modelo (que podría ser aplicable a otros casos) que podemos resumir como el de los cuatro ciclos de vida, cuatro modos de existencia distintos según el sitio esté inmerso en universos distintos; los tres "normales" más que el que deberíamos procurar que adquiera desde una intención social de valorización y uso del patrimonio: el social original (cuando se crea y funciona el sitio), el post-deposicional (cuando se abandona), el moderno (instanciado a partir de su recuperación), y uno de reincorporación a la vida social, hacia el que deberíamos orientarlo en la actualidad. En lo sucesivo, vamos a tratar de argumentar esta visión.

\section{PUNTO DE PARTIDA: ALTAMIRA EN CRISIS}

Empecemos por la cueva de Altamira. Fue en los años 70 cuando fueron detectadas colonias de bacterias que ponían en riesgo la conservación de las pinturas rupestres. Existiendo el precedente de Lascaux (cerrada en 1963), en 1977 se decretó el cierre pro- 
visional de la cueva, mientras se realizaban estudios para determinar su estado de conservación. En 1982 la cueva fue reabierta, pero el flujo de visitantes se redujo de las más de 150.000 a 11.320 personas por año (Programa Altamira 2014b: 20, 61). En 1991 ocupó la dirección de Altamira José Antonio Lasheras, lamentablemente fallecido en accidente de tráfico en febrero de 2016. José Antonio fue clave en el planteamiento de una nueva estrategia, en la que trabajó desde su llegada, que incluía un museo totalmente nuevo y una réplica concebida como estructura expositiva que suministrase la información didáctica sobre la cueva (a la que se denominó Neocueva; Lasheras 2006). Por ello se eligió hacer una réplica que recreaba las condiciones originales y rehundía artificialmente el suelo de la cueva para recrear el nivel del techo en las épocas en que fueron realizadas las pinturas, y para que los visitantes pudiesen circular y contemplar las mismas (Múzquiz y Saura 2003; Lasheras 2004).

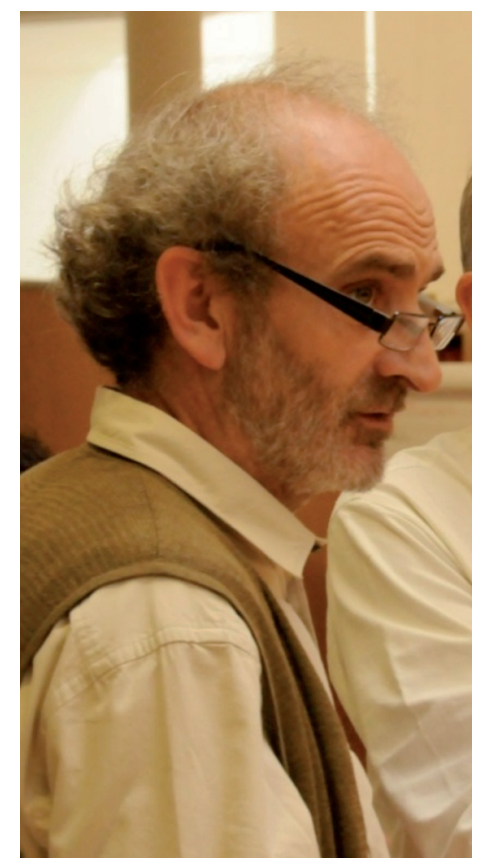

Figura 1. José Antonio Lasheras en 2013. Fuente: Incipit.

Lo que poca gente sabe, acostumbrada a pensar que la Neocueva era en realidad una infraestructura sustitutiva de la cueva original, es que en la concepción de José Antonio Lasheras la réplica fue pensada para funcionar como complemento a la original. Su idea era dar toda la información práctica sobre la cueva en la réplica y abreviar así el tiempo de visita a la original, a la que los visitantes pasarían, después de empaparse de información en la Neocueva y en el Museo, para tener una experiencia sensorial y emocional del original. 


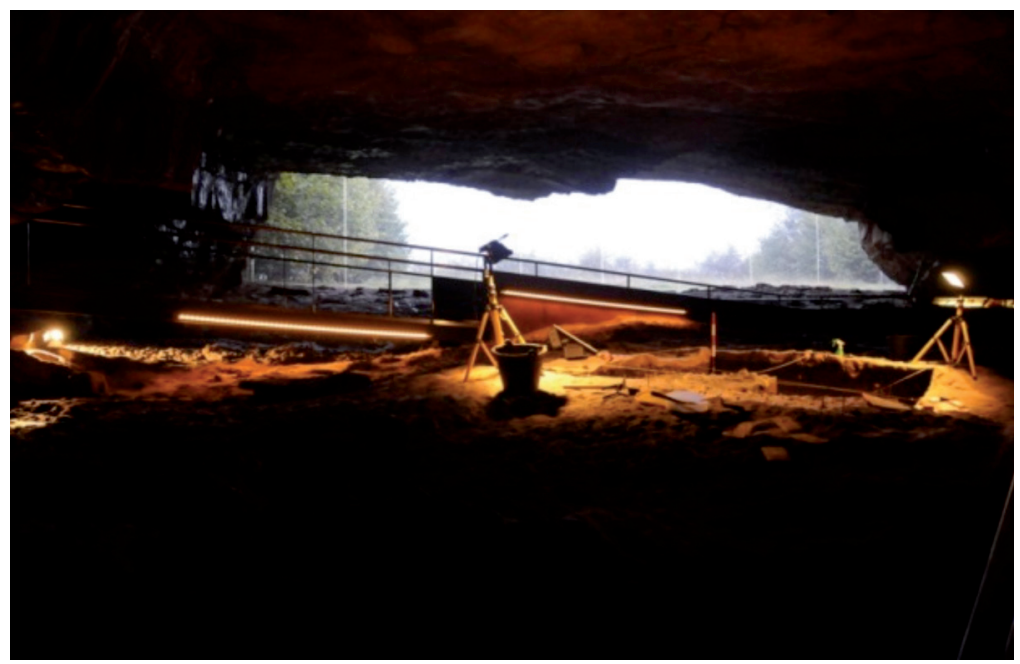

Figura 2. Una imagen de la entrada de la Neocueva desde su interior. Fuente: Incipit.

El nuevo museo se abrió en 2001. Pero en 2002, ante la aparición de nuevos indicios de contaminación, el Patronato de la Cueva de Altamira decidió el cierre provisional de la cueva. Los estudios y la complicación de las posibles soluciones prolongaron el cierre, llegando a naturalizar la idea de que la cueva original debía permanecer cerrada para asegurar su preservación mientras se compensaba al público con la visita a la Neocueva. Nosotros sabemos bien esto ahora, pero desconocíamos esta idea y compartíamos la imagen tópica del cierre de Altamira (como cualquier ciudadano español informado) antes de empezar nuestra inmersión en Altamira.

Esta naturalización de la idea del cierre de la cueva influyó en que, por oposición, empezase poco a poco una presión, sobre todo ejercida desde el Gobierno de Cantabria y amparada por los intereses del sector turístico y las reclamaciones comunitarias, a favor de la reapertura de la cueva. Estas reclamaciones se hicieron especialmente intensas entre 2010 y 2012. La mayor parte de los especialistas y los medios de difusión nacional, en cambio, se mostraron en contra. Aquí se vio ya, como nuestros estudios posteriores mostraron, una de las disfunciones del régimen político de la Transición, que fue incapaz de resolver debidamente la pulsión entre la inercia centralista de la visión unitarista de España y el intento de descentralización que suponía el Estado de las Autonomías. El mismo desconocimiento del otro, del que es periférico a las condiciones de cada uno, que provocó las carcajadas de casi 10 millones de espectadores con "Ocho apellidos vascos", hacía que al sur de El Escudo no se entendieran las razones cántabras ni que al norte del puerto se entendiera la reacción contraria de todos los demás.

Para salir de este impase, en 2012 fue lanzado el referido Programa, que pretendía generar datos que permitiesen a los responsables del sitio (declarado Patrimonio Mundial en 1984; ampliado en 2008 a otras 17 cuevas de la Cornisa Cantábrica) tomar una decisión in- 
formada sobre al acceso público al bien: "se trataba de evaluar la incidencia de la dinámica natural actual de la cueva, el impacto de la presencia humana en la conservación de la cueva y de sus pinturas rupestres, definir los protocolos de acceso de investigadores y eventuales visitantes y diseñar las medidas de conservación preventiva” (Programa Altamira 2014a: 9).

Una de las consecuencias del Programa fue la apertura restringida de la cueva a cinco personas por semana, de modo experimental, primero durante un año natural, pero con opción a continuar el régimen: "El régimen de visitas experimentales actual debe mantenerse hasta finales de febrero de 2015, con el fin de cumplir un ciclo anual que permita analizar el impacto en las distintas estaciones. A partir de entonces, se recomendará continuar con las visitas, bajo el mismo régimen, o bien introducir modificaciones", Programa Altamira 2014c: 38).

Esto es lo que llevó a numerosos especialistas a señalar que la intención del Patronato, a través del Programa (que, según estos especialistas, se habría promovido dejando al margen una serie de informes desarrollados desde el CSIC, contrarios a cualquier tipo de apertura, cuyas conclusiones se encuentran sintetizadas en Sáiz et al. 2011) siempre había sido la apertura de la cueva al público, aunque fuese de forma restringida. Lo cual estaría demostrado, entre otras cosas, por la elección de un responsable acorde con esa intención (Departamento de Prehistoria de la Universidad Complutense de Madrid, 2014, 2016). Esta declaración fue publicada en diferentes medios digitales y de su impacto se hizo eco la prensa nacional (por ejemplo, Altares 2015).

Nuestra propuesta no pone el foco en el aparente dilema entre uso y conservación, y no es por eludir tal dilema (como ya pusimos de manifiesto públicamente en su momento; Ayán et al. 2015). O, mejor dicho, no ponemos el foco en la necesaria conservación de la materialidad de las pinturas (algo en la que ya existen especialistas que mantienen debates y discusiones sin duda interesantes, aunque sean de difícil acceso al público general, como el compendio de aportaciones recogidas en Sáiz 2014) sino en el contexto sociopolítico (pasado y actual) en el que este dilema se pone de manifiesto, y en la necesidad de que cualquier estrategia de gestión del sitio tenga en cuenta los condicionantes sociales, no sólo los parámetros de conservación de la materialidad del bien. A esto es a lo que se refiere la evaluación de riesgos que hicimos en su momento, como veremos más abajo. Pero, para comprender la compleja situación actual como un momento de un proceso, es necesario entender las fases de dicho proceso.

\section{LAS TRES VIDAS DE ALTAMIRA: SIGLO XX Y PATRIMONIALIZACIÓN}

Lo que ahora es conocido como Cueva de Altamira fue, durante el Paleolítico Superior, parte de un espacio vivido (Lasheras 2003). La caverna tenía, probablemente, el rol de un lugar de agregación, con una alta carga simbólica y una topografía peculiar, que la hace, paradójicamente, estar "cerca del cielo". Es una cueva muy distinta a muchas otras 
cuevas porque más que una sima en el interior de una montaña, es un espacio cerrado, oscuro, en el interior de una dorsal topográfica, situado casi en superficie y tocando el cielo. Este rasgo formal de Altamira fue recogido por el diseñador del afortunado logo del $\mathrm{Mu}$ seo de Altamira, Jacobo Pérez Enciso, ganador del concurso de ideas celebrado en 2001, que resalta precisamente este carácter de un sitio cubierto, pero superficial (véase figura 3). En comunicación personal con el autor, éste nos transmitió que lo que pretendía contar, después de haber hablado muchas veces con José Antonio Lasheras, es que había una sociedad mucho más rica y más compleja de la imagen que podemos tener. Para ello, hizo algo muy simple: diseñó un cuadrado y actuó sobre el 10 o 15\% superior del cuadrado, indicando así que todo lo que estamos viendo del mundo al que nos referimos es una parte mínima del mismo, y que hay mucho más. En el cuadrado sólo entra la palabra "museo", para reflejar que, de un mundo tan complejo y tan rico, lo que vemos es sólo la superficie.

Todo apunta a que Altamira ya tuvo en época prehistórica una identidad propia, por lo que podemos entender que era un lugar (un encuentro entre múltiples trayectorias espaciales y temporales, en el sentido que le confieren Doreen Massey -2005- o, refiriéndose a los espacios de la sobremodernidad, Marc Augé 1993). Esta vida prehistórica es lo que nosotros entendemos como primera vida.

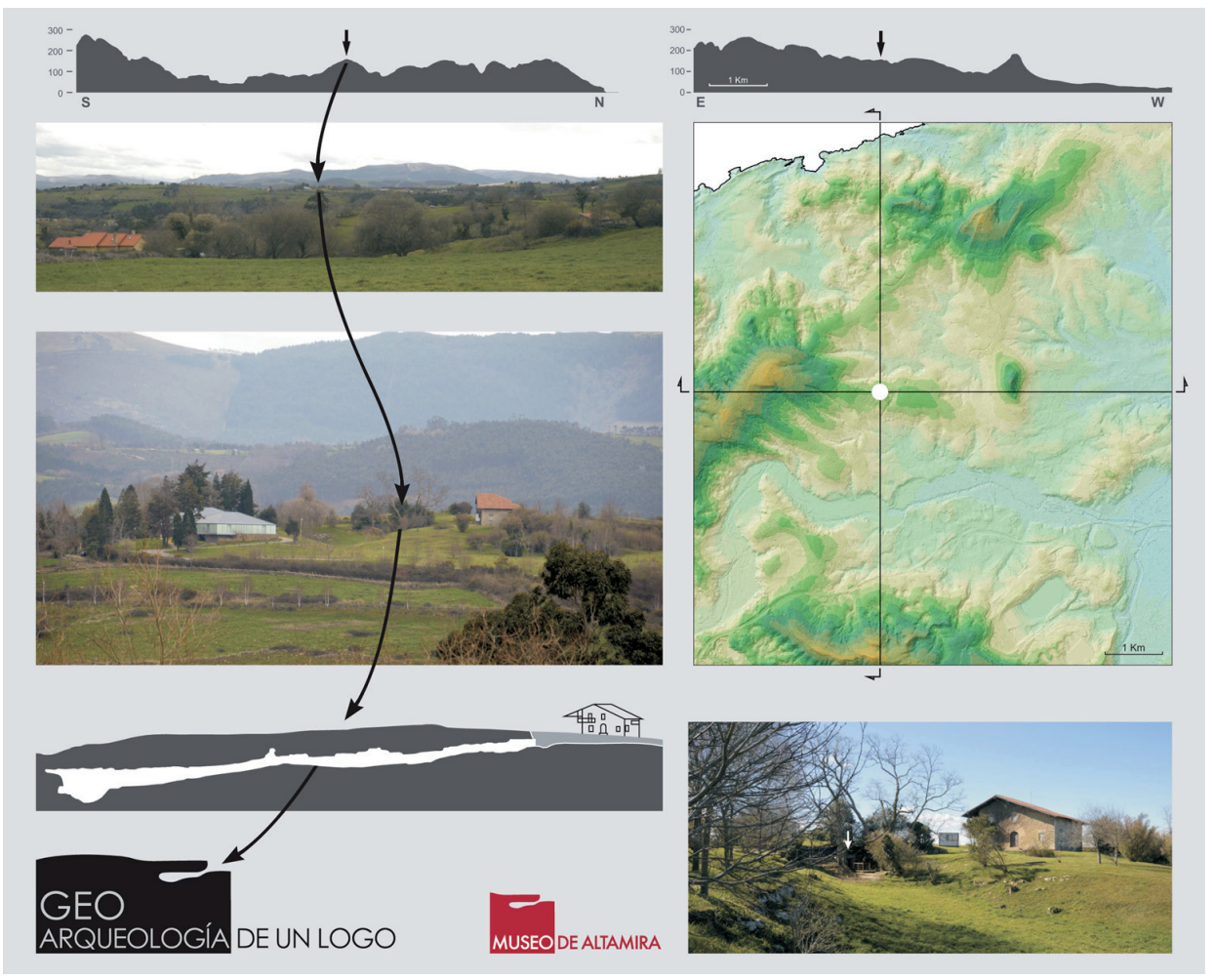

Figura 3 
Hace 13.000 años colapsó la amplia entrada de la cueva, que era abierta, como quedó perfectamente reflejado por la Neocueva, y aquella quedó sumida en un largo letargo, ajena a la sucesión de horizontes culturales diversos, para los cuales no existía. Por lo tanto, dejó de tener una identidad, de ser un "lugar". A este largo período de "inexistencia social" lo denominamos segunda vida de Altamira. Fue un ciclo de vida sin presencia humana, una época durante la que Altamira se comportó como un nicho para las especies biológicas y procesos naturales que acaecían en ella.

El descubrimiento de las pinturas saca a la cueva de este largo letargo social. Lo que en su momento denominamos tercera vida de Altamira es la existencia contemporánea del sitio (no es ningún eufemismo para ocultar nuestro supuesto deseo de abrir la cueva al público, ni tiene nada que ver con ello, al contrario de lo que sugiere Junyent 2016: 362). Esta tercera vida se inicia cuando la cueva es descubierta y reintroducida en el mundo humano-social. Esta vida ha pasado por dos estadios bien diferenciados (que denominamos Vida 3.1, y Vida 3.2), en cada uno de los cuales primó un criterio esencialista (patrimonio como signo identitario) o técnico-instrumental (patrimonio como objeto de gestión). Nuestra investigación de estas vidas nos ha permitido identificar los problemas que plantea cada uno de ellos y los conflictos con la identidad del sitio a los que dieron lugar. Sobre esta base planteamos la necesidad de que Altamira, como creemos que debería pasar en muchos otros sitios patrimonio de la humanidad y, de hecho, en cualquier yacimiento arqueológico puesto en valor, alcance una nueva vida, una vida futura distinta a todas las anteriores. Una cuarta vida que, nuevamente, debemos señalar que no tiene nada que ver con la posibilidad de acceder (o no) físicamente a la cueva, sino con la plenitud de Altamira (que es algo más que una cueva con pinturas) como lugar de socialización.

\section{LA VIDA 3.1 DE ALTAMIRA: SER MONUMENTO}

A finales del siglo XIX, el descubrimiento de la cueva (en 1868) y de las pinturas (en 1879) supuso la vuelta a la vida social de lo que se dio a conocer como Cueva de Altamira (De Las Heras 2003). El descubrimiento de las pinturas se atribuye a Marcelino Sanz de Sautuola, lo que oculta dos significativos errores. El primero es que el descubridor de la cueva fue un vecino local, Modesto Cubillas, que se lo comunicó al anterior, patrón de él, rico propietario y erudito reconocido. El segundo es que el descubrimiento de las pinturas lo realizó en realidad su hija de ocho años, María Sanz de Sautuola y Escalante, abuela de Emilio Botín, lo que tuvo notable impacto en la vida futura de la cueva al crear una relación preferente entre éste (y la Fundación Botín) y la cueva, algo que benefició en gran medida a Altamira y a la materialización del proyecto del nuevo museo y la Neocueva. 
Figura 4. Ilustración de Joan García Junceda correspondiente a manual escolar de 1942 (Muntada Bach. Santa tierra de España). Fuente: Manuales Escolares Españoles, Biblioteca central de la UNED.

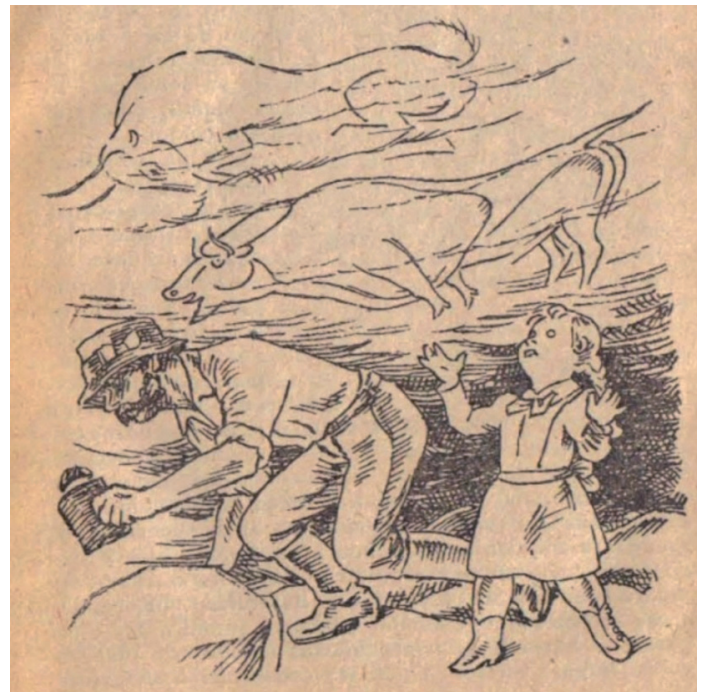

La autenticidad de la cueva no fue certificada hasta 1902, cuando Émile Cartailhac publicó su artículo La grotte d'Altamira, Espagne. "Mea culpa” d'un sceptique. Esta demora en el reconocimiento fue interpretada por la historiografía posterior como una consecuencia de la posición subalterna de España respecto a los países pujantes de Europa (en este caso, especialmente, de Francia) y utilizada en la construcción de un discurso victimista y simplificador, muy dramático (como se puede apreciar con el reciente estreno de la película Altamira, protagonizada por Antonio Banderas), pero que parece que no se corresponde totalmente con la complejidad de la realidad histórica (como se han encargado de señalar Moro 2009 y Hochadel 2013: 35-41). Lo que sí es cierto es que, desde su descubrimiento, Altamira estuvo condicionada por las vicisitudes políticas y económicas del Estado responsable de su cuidado (España), al tiempo que se convertía en una entidad relevante a nivel local, regional, nacional e internacional, con una historia intrincada y controvertida sobre su gestión y adecuación para la visita (Moro 2009).

En una etapa inicial (hasta los años '20) la cueva fue gestionada por el ayuntamiento de Santillana del Mar, pero los problemas de deterioro exigían una actuación de rehabilitación demasiado costosa. Así fue como la gestión de la cueva (que no la propiedad) pasó a manos del Estado, personificado en el Duque de Alba (Programa Altamira 2014b: 28), quien, como presidente del Consejo Superior de Excavaciones y Antigüedades y amigo del rey Alfonso XIII (1903-1931), se puso al frente de una Junta de Administración en la que participaban los poderes locales.

En 1925 ya existía una primera carretera de acceso a la cueva, funcionaba el Museo (que incluía una casita para el vigilante de la cueva) y se iniciaba un primer proyecto de adecuación de la cueva a la visita, al tiempo que Altamira era declarada monumento 
nacional. Así es como pasó a convertirse en un símbolo nacional, al igual que otros elementos arqueológicos (por ejemplo, Numancia), que supuestamente remitían a un pasado nacional glorioso, representativo del camino de la nación española en la historia. Este proceso se veía reforzado por la presencia recurrente de Alfonso XIII, que durante la década de los años '20 solía veranear en Santander y visitar la Cueva cada año.

Tras el paréntesis republicano (1931-1939), durante el cual todo monumento nacional pasó a ser monumento histórico-artístico (denominación que se mantuvo hasta 1985), la cueva estuvo a punto de ser destruida por la Legión Cóndor (que bombardeó primero Santander y después Guernica, entre otros sitios) durante la Guerra Civil. La intermediación de un comandante franquista (Alfredo Kindelán) la salvó. Y Altamira vio reforzada su condición de símbolo tras la guerra, con la creación del Patronato de la Cueva de Altamira en 1940, que dependía de Madrid. En 1944 los poderes locales dejaron de estar representados en el Patronato. El régimen de Franco daba mucha importancia a este espacio patrimonial y la ideología nacionalista se apoyaba en esta dimensión simbólica, al tiempo que la reforzaba, asumiendo el control total de su gestión.

A medida que España salía de la depresión de la posguerra, y empezaban los años del desarrollismo, y gracias a la difusión de los medios de comunicación de masas (véase RTVE 1955), a la generalización de los medios de transporte y a la creciente movilidad turística de la emergente clase media, se incrementaba cada año el número de visitantes. Entre 1955 y 1973 el número de visitas anuales creció desde 55.000 hasta 175.000. Al mismo tiempo se acometieron obras de mayor o menor calado para adecuar el espacio de la cueva y alrededores a las visitas y para intentar frenar los síntomas de deterioro que empezaban a detectarse (Programa Altamira 2014b: 47).

A principios de la década de 1960 se realizan las primeras réplicas: dos reproducciones fotogramétricas del techo de la Sala de Polícromos, a cargo de investigadores alemanes (una se instala en Múnich y otra en Madrid, en los jardines del Museo Arqueológico Nacional; RTVE 1964). Todo ello ocurre sin perder su carácter emblemático-nacional, y combinado con un modo de gestión asentado en relaciones vinculadas al prestigio y al carisma de los poderes fácticos en el entorno local y regional, que sostenían el régimen de acceso y las visitas guiadas, así como el funcionamiento del Museo. Mientras tanto, el Ayuntamiento de Santillana seguía pugnando por el control directo de la gestión (Programa Altamira 2014b: 54).

\section{LA VIDA 3.2 DE ALTAMIRA: SER PATRIMONIO}

En 1977 la gestión es asumida por el Ministerio de Cultura, y la propiedad pasa definitivamente a manos del Estado, a lo que accede el Ayuntamiento (que renuncia a la vía judicial que había iniciado en 1969 para recuperar la titularidad de la cueva, a cambio de compensaciones económicas). Recordemos que, entre 1977 y 1982, la cueva permanece cerrada para la realización de un diagnóstico detallado sobre su estado de conservación 
y las medidas preventivas a adoptar (Programa Altamira 2014b: 52 y ss.). Mientras tanto, como un modo de saciar la curiosidad de los numerosos visitantes a la cueva, que se encontraban, a su llegada, con una verja cerrada, en 1979 se crea el Museo Nacional y Centro de Investigación de Altamira ("un instrumento científico y administrativo para la mejor gestión y conservación de la cueva de Altamira", como reza la página web del Museo), que asume la gestión y sigue ocupando las dependencias ya existentes, recientemente ampliadas con la construcción de tres pabellones para la recepción de visitantes y una cafetería.

En 1985 se aprueba la nueva Ley de Patrimonio Histórico Español, que pretendía implementar los modos modernos de gestión, protección y conservación de los bienes patrimoniales, cambiando entre otras cosas las figuras de protección. Altamira "perdió" así su condición de "monumento" y se convirtió en un bien de interés cultural, asociándose a la idea de sitio, de conjunto de elementos integrados en un entorno protegido, más que a la de un ente aislado. Este mismo año se firmó un convenio entre administraciones (incluida la regional) donde se modificaba la composición del Patronato ("cediendo" al presidente autonómico la presidencia del mismo), al tiempo que Altamira era declarada Patrimonio Mundial por la UNESCO.

Por todo ello, 1985 podría haber sido el inicio de una modernización modélica en la gestión del bien, pero se dieron dos grandes problemas, los mismos que tuvo la modernización asociada a la Transición política en España: 1) se asentó sobre estructuras económicas, políticas y sociales preexistentes (en Altamira seguían vigentes las prácticas clientelares de gestión de la cueva anteriores a las decisiones del periodo 1977-1985) y permanecieron casi intactas las viejas oligarquías locales y nacionales, muchas de ellas nacidas gracias a la incautación de patrimonios familiares posibilitada por el régimen franquista; y 2) no resolvió el problema del modelo territorial, que en Cantabria se manifiesta con una fuerte dicotomía identitaria entre nacionalismo español y regionalismo, y se traduce en conflictos en torno a la tutela y gestión de Altamira.

Lo segundo se vio acompañado por otra circunstancia especial de la Transición española. Uno de los problemas originales de ésta fue su contradicción porque operó simultáneamente en dos direcciones opuestas en lo que se refiere al modelo territorial. Por un lado, la Transición supuso la democratización del régimen franquista y el intento de culminar la modernización de España que estaba pendiente desde las Cortes de Cádiz; esto suponía la modernización de la Administración General del Estado y funcionó a favor de la concentración del poder en el gobierno central y Madrid. Por otro lado, la nueva Constitución del 78 estableció un modelo territorial del Estado totalmente nuevo basado en las Autonomías y en una versión edulcorada de un auténtico Estado Federal en el que la concesión de ciertas cotas de autogobierno a todas las regiones españolas funcionó como amortiguador de la demandada y necesaria concesión de autogobierno a las Nacionalidades históricas (Euskadi, Catalunya, Galicia). Como en tantas otras cosas, también en Altamira se sintieron las contradicciones surgidas al darse los dos procesos al mismo tiempo: se moderniza y refuerza el modelo de gestión desde Madrid, al tiempo 
que se construye una Autonomía hasta ese momento inexistente, la cántabra que, por su propia inercia, habría de dar lugar a reclamaciones y conflictos en torno a Altamira.

Hay que insistir un poco más en esto. Santander había sido desde 1833, por mor de la nueva división territorial de España en regiones y provincias abordada por los liberales (con la doble intención de modernizar el Estado y conciliarse con los carlistas), una provincia de Castilla la Vieja, y la ciudad de Santander el puerto natural de la misma. Aunque el "cantabrismo" (expresión política de las especificidades propias de Cantabria) hunde sus raíces en el XIX y tuvo un momento de eclosión antes de la Guerra Civil al proponer un Estatuto de Autonomía para Cantabria dentro de la República Federal Española, el franquismo anuló y adormeció estos proyectos hasta que se recuperaron con la Transición. En 1978 un cantabrismo reemergente se opone a la inclusión de la provincia de Santander en el proyecto de Estatuto de Autonomía para Castilla y León, funda el Partido Regionalista de Cantabria, e inicia un proceso de reclamación de una autonomía uniprovincial que culmina con la aprobación de la Autonomía cántabra en 1981. El momento simbólico que supuso el punto de fisura en la expresión política del nuevo cantabrismo fue la reclamación de la reapertura de la cueva (Fatás 2011:76) y el encadenamiento de sus dirigentes históricos a la verja de la cueva de Altamira en 1978. En las fotos de aquel acto aparece un joven Miguel Ángel Revilla, operando como maestro de ceremonias (asa y reparte sardinas a la concurrencia). Poco después se funda el Partido Regionalista de Cantabria, del que llegará a ser presidente Revilla. Desde ese momento, Altamira y el cantabrismo quedan enhebrados en una conjunción que se opone a la visión centralista de España, que también había usado y usará todavía Altamira como "marca España". Mientras tanto, el momento político trabaja a favor de ambos intereses alimentando la contradicción entre ellos: se refuerza en Altamira la presencia del Gobierno Central a través del nuevo régimen del Patronato de Altamira y la creación del museo nacional, y se pone en marcha un proceso autonómico que, en el caso de Cantabria, tomará a Altamira como símbolo de unidad y legitimidad.

Las dos legitimidades se van desarrollando poco a poco. La modernización del museo y del modelo de gestión, bajo la dirección y personalidad de José Antonio Lasheras, concilió ambas perspectivas y amortiguó, con su indudable carisma y originalidad, las tensiones entre ellas. En apenas 10 años desde que él toma posesión de la dirección de Altamira, se inaugura en 2001 la sede actual del museo (un edificio nuevo, plenamente integrado en el entorno, para el cual se modificaron los accesos, alejándolos de la entrada de la cueva), y se incorpora la réplica de gran calidad de la Sala de Polícromos, elaborada de forma artesanal, combinada con distintos elementos museográficos que nos ilustran sobre el contexto habitacional de las sociedades paleolíticas y sobre el trabajo arqueológico (Múzquiz y Saura 2003). El programa del Museo se concibió como una ilustración de los modos de vida prehistóricos, a cambio de renunciar a contar la historia de la tercera vida de Altamira, la historia de su existencia contemporánea y sus vicisitudes actuales (a excepción de una pequeña sala dedicada al descubrimiento de la cueva). 


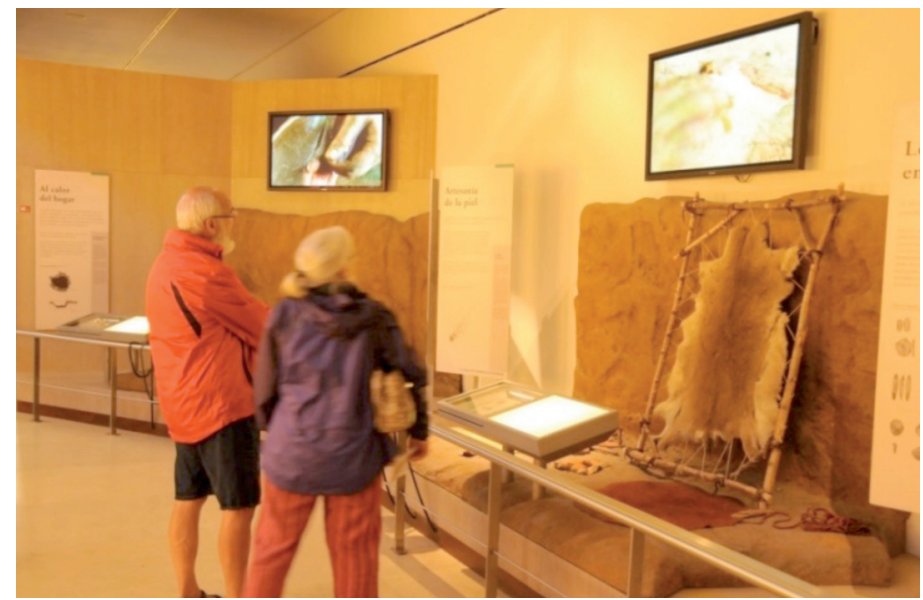

Figura 5. Dos visitantes en el interior del museo. Fuente: Incipit.

Mientras tanto, se mantuvo una gestión centralizada que tensiona las relaciones entre el personal responsable directo del museo (dependiente de Madrid) y los poderes locales y regionales, al tiempo que propicia un alejamiento existencial de la población local respecto al sitio y una percepción de marginación respecto a los modos de gestión de la cueva y el museo. El cierre de la cueva, en 2002, agudizó estas tensiones, instrumentalizadas por el Gobierno Regional de Cantabria con el fin de reclamar su apertura al público, en un proceso de construcción de una identidad regional inexistente hasta 1978 (Fatás 2011:76).

\section{HACIA LA CUARTA VIDA NECESARIA: SER DE NUEVO UN LUGAR}

En una reciente publicación, Gustaffson y Karlsson (2014) analizaron los modos de gestión de ocho enclaves patrimoniales con arte rupestre, entre ellos Altamira (Gustaffson and Karlsson 2014: 165-175). Lo hicieron basándose en el concepto de "autenticidad", tal y como se recoge en la Declaración de Nara sobre la autenticidad (ICOMOS 1994) y en la Carta de Ename para la Interpretación y Presentación de Sitios de Patrimonio Cultural (ICOMOS 2007). Este concepto supone todo un desafío a la hora de gestionar el patrimonio, pues implica potenciar su uso social en combinación con las necesidades de protección y preservación del soporte físico y el entorno. En casos como Altamira, esto supone un aparente dilema imposible de resolver de forma satisfactoria y razonable: o se usa o se protege. Hay que insistir en que, para muchos expertos, ciertamente, esto no supone ningún problema; la conservación prima sobre el uso. A no ser que busquemos otras formas de uso.

Gustaffson y Karlsson se refieren en términos bastante críticos al modo en que Altamira es gestionada en la actualidad. Se refieren, por ejemplo, a que el discurso científico es transmitido al público «with self-confidence and in a clear, loud, scientific and 
dominant voice» (Gustaffson and Karlsson 2014: 174). Estando apenas a 150 metros de la cueva original, no se invita a los visitantes a acercarse a la entrada (hay un circuito definido que marca las distancias), lo que supuestamente contradice los principios de la autenticidad. Para estos autores, la extrema fragilidad de las pinturas originales podría justificar que no se pueda entrar en la cueva, pero no el modo en que se aleja al visitante del motivo principal de la visita, ni la ausencia en el discurso de voces distintas a las de los científicos.

En este sentido, es de justicia destacar aquí el proceso de renovación en el que se halla inmerso el Museo desde 2017, con una inversión muy importante por parte del Ministerio de Cultura y Deporte para mejorar el acondicionamiento del espacio del Museo (incluida la Neocueva), renovar la exposición permanente, crear un nuevo espacio (el Paisaje de Altamira) y musealizar la contigua cueva de las estalactitas ( lo cual sin duda redundará en una mejora sustancial de la visita al sitio. Al mismo tiempo, la Comisión de Seguimiento del Plan de Conservación Preventiva acordó nuevas acciones encaminadas a obtener más información sobre los parámetros de conservación de la cueva y la estacionalidad de las alteraciones (Ministerio de Cultura y Deporte 2017).

Figura 6. Vista de la zona de acceso a la entrada de la cueva, desde el camino habilitado para los paseantes por el entorno del museo. A la derecha, la antigua caseta del guarda. Fuente: Incipit.

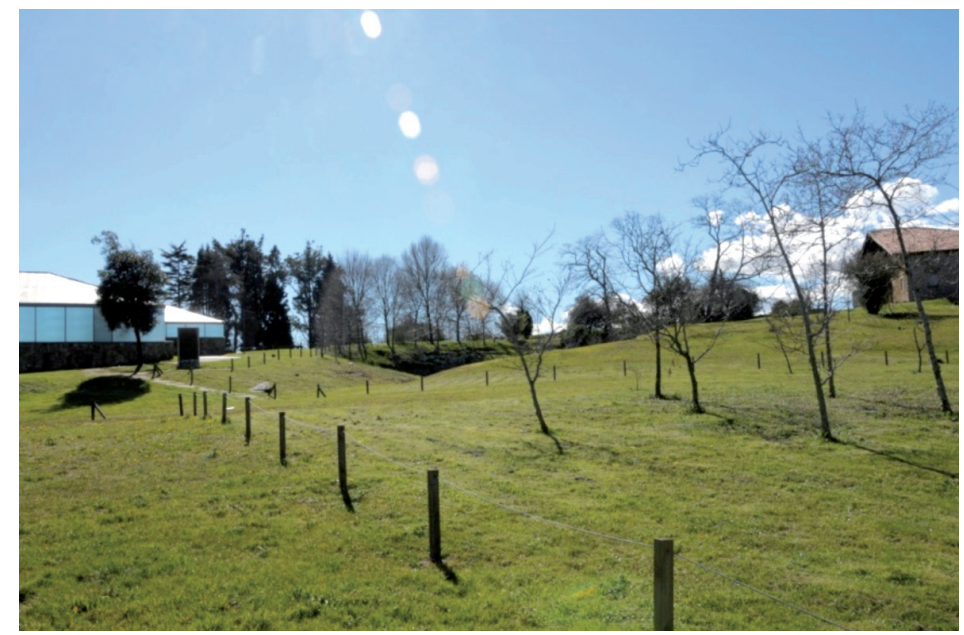

Independientemente de la cuestión de la preservación física y de la decisión concreta al respecto, tenemos que aceptar la idea de que Altamira (como muestran los diversos estudios que el Incipit realizó en el marco del proyecto citado, especialmente los estudios sociológico y antropológico) es un fenómeno en el que todos los agentes sociales desempeñamos roles; $y$, por lo tanto, todos estamos poniendo algo en juego (sea más o menos). En consecuencia, aplicando uno de los principios básicos de la "ciencia posnormal" (que también podemos llamar ciencia con la gente o ciencia pública, que establece que todas 
las personas afectadas por una decisión deben ser tenidas en cuentas al tomar ésta; Funtowicz y Ravetz 2000), todos los agentes sociales, expertos o no, deberíamos tener voz en el debate acerca de su futuro. Esto no implica minimizar el papel de los expertos, sino contextualizar sus aportaciones en un debate político más amplio. Ha pasado el tiempo en el que los expertos (los científicos) éramos un agente social privilegiado que podía decir al mundo lo que había que hacer sin necesidad de dar explicaciones. Pero también ha pasado el momento, santificado primero por el posmodernismo y ahora mismo por el giro "fake" hacia la alt-reality, en el que los expertos nos teníamos que disolver frente a lo que dijese cualquier otra persona diluyendo nuestra razón experta dentro con más o menos generosas dosis de "populismo epistémico" (Grosfoguel 2011). En cambio, tenemos que reclamar la capacidad de construir y ofrecer un conocimiento crítico, no autoritario, capaz de incorporarse a los grandes debates sociales sin tener que pedir perdón por hacerse presente, o mendigar la aceptación de la gente: tenemos que provocar, educar y evitar los cantos de sirena de la Cruzada Patrimonial (González-Ruibal et al. 2018; Lowenthal 1998). O, como decía recientemente Ken Loach en unas declaraciones, tenemos que "agitar, educar y organizar" (https://www.revistarambla.com/dirigir-los-esfuerzos-la-sociedad-tres-principios-claves-agitar-educar-organizar/ ).

Desde esta perspectiva podemos entender mejor nuestra posición respecto a la polémica sobre la apertura de la cueva.

Desde nuestro punto de vista, el problema central es que no hay una solución óptima (ni mucho menos universalmente aplicable). Lo que hace falta es propiciar un contexto de discusión-acción más amplio, no copado en exclusiva por el criterio experto ni por el demagógico (si el primero es el que ha dominado la parte científica del escenario, como representa perfectamente Saiz-Jimenez et al. 2011, el segundo es el que ha acompañado a Revilla y a la parte cantabrista del debate), y donde en cambio adquiera relevancia la identidad de Altamira como fenómeno social en torno a un sitio específico.

Para nosotros esto se concreta en que debemos entender Altamira como una entidad viva, y que por lo tanto debe aspirar a una vida nueva. A que sea un sitio distinto a lo que ahora es; un lugar más que un monumento, un lugar, mejor que un sitio en su sentido convencional, en el que se produce sociedad en torno a las diferentes dimensiones existenciales que se dan en ella: estéticas, éticas, cognitivas, pedagógicas...

Este horizonte de reflexión va mucho más allá de Altamira. Ofrece referencias que también deberían servir para otros sitios y proyectos patrimoniales. La gestión del patrimonio tiene que ir mucho más allá de la mera gestión, y de la mera puesta en valor: tiene que aspirar a convertir los bienes y espacios en nuevos lugares de socialización, y tiene que realizar una prospectiva reflexiva acerca de las consecuencias que nuestras acciones ocasionarán en el futuro, incluyendo aquellas que puedan frenar o acelerar la transformación material de un lugar. Porque lo que está claro es que, hagamos lo que hagamos, los lugares se crean y recrean a través de nuestra acción.

Declarar un sitio como Patrimonio Mundial, o simplemente ponerlo en valor, valorizarlo a través de inversiones de trabajos y recursos, incardinarlo en el proceso turístico, 
acabará por convertir ese sitio en otra cosa distinta a lo que era antes de su declaración como tal. Por lo tanto, nuestra acción debe ser reflexiva e intentar marcar las pautas de su evolución futura, prever los nuevos modos de existencia de estos espacios patrimoniales. Para ello debemos anticiparnos a los acontecimientos, en la medida de lo posible, a través de una evaluación de riesgos crítica, no meramente técnica. Esto no se puede hacer sin el concurso de los agentes sociales.

El Programa de Altamira finalizó en agosto del 2014 con la definición de un Plan de Conservación Preventiva, que es el que más o menos se está siguiendo en la actualidad. En él se incluía una evaluación de riesgos organizada en fichas individualizadas (una para cada riesgo). Nuestra investigación permitió realizar también una evaluación de una serie de riesgos desde esta perspectiva socializadora. Analizamos y caracterizamos esos riesgos utilizando el mismo lenguaje técnico e instrumental que el resto de los estudios del Programa, pero orientamos nuestro diagnóstico no hacia los riesgos sobre la materialidad del bien, sino hacia los riesgos sociales asociados al modo de gestión de dicho bien.

Identificamos cuatro grandes riesgos en el caso de Altamira (números 3, 4, 5 y 7 de la lista siguiente). Ampliando nuestro análisis de Altamira con los análisis del modo de funcionamiento y evolución de otros proyectos de valorización de sitios (sea Santiago de Compostela, o sea la gestión de los cascos históricos o los Parques de la Rede do Patrimonio Arqueolóxico de Galiza -Campo Lameiro y San Cibrán de Lás-), podemos enumerar siete riesgos que, indefectiblemente, constituyen las etapas sucesivas por las que pasará el sitio para convertirse al final en sitio distinto y, nos tememos, sitio irreconocible.

1. Fractura entre el sitio y la administración de la que depende.

2. Fractura entre el sitio y las autoridades locales.

3. Fractura entre el sitio y su entorno social inmediato (comunitario).

4. Desvalorización del sitio como factor de atracción patrimonial.

5. Desvalorización y mercantilización de la imagen del sitio.

6. Fractura entre el sitio y su entorno social de media distancia (regional).

7. Generación y/o agravamiento de conflictos identitarios.

Por lo que se ve en la literatura, en experiencias propias y ajenas en otros sitios (NEARCH 2017), estos riesgos aparecen, antes o después, en cualquier sitio patrimonio mundial (un incipiente desarrollo conceptual de esta primera propuesta puede verse en Barreiro y Varela-Pousa 2018). Son, de hecho, tan frecuentes y recurrentes, que habría que empezar a considerarlos como males generales y prepararse a priori para enfocarlos y corregirlos. Su estudio y definición va más allá de lo que es hacer un risks assessment, incluso de las más avanzados en términos de trabajo con la comunidad y sostenibilidad (ICCROM-CCI 2016; Pastor 2016; Pastor y Canseco 2016). Porque, en realidad, a estas técnicas y métodos, que son necesarios, habría que incorporar las técnicas de trabajo desarrolladas dentro del campo de la prospectiva y los estudios del futuro (ie: ver congresos Prospecta, https://prospecta.unad.edu.co/), de cara a poder analizar la evolución de la vida y las condiciones probables de existencia de los sitios arqueológicos, una vez 
declarados World Heritage. Hay que entender esta propuesta como un ir más allá de una identificación de los riesgos en términos más o menos innovadores, que es lo que aquí hemos apuntado, para llegar a analizar tanto las subjetividades como los datos objetivos, desde la crítica y con el compromiso absoluto de las disciplinas implicadas (véase un buen ejemplo desde la antropología en Low 2014), y hacerlo prospectivamente: no se trata sólo de entender el contexto social e implicarse en su transformación, sino de proyectar nuestra acción hacia el futuro, intentando apreciar y dimensionar el rol que juega el proceso patrimonializador en dicha proyección (Barreiro y Varela-Pousa 2018).

Sin embargo, en el Programa Altamira, y a pesar de nuestro esfuerzo adaptativo a las condiciones del juego interdisciplinar en el que participábamos, nuestra propuesta quedó reducida a una única ficha sobre "Fractura entre Altamira y el entorno social", desoyendo nuestras advertencias basadas en nuestros análisis y datos. Pero sí se incluyeron otros riesgos asociados a la interacción sociedad-Altamira (como "visita cultural", "entrada de investigadores" o "actos antisociales"). Ello evidencia la persistencia del paradigma técnico-instrumental, que construye el objeto de modo que éste se convierte en su única cuestión de interés (es decir: lo que importa es la protección del objeto patrimonial, no la del sujeto que valora y disfruta el patrimonio, cuando es este sujeto el que justifica la propia existencia del patrimonio y sobre el que deberían evaluarse, además, los riesgos inherentes a la patrimonialización).

Lo que acontezca con los usos del patrimonio, sus manejos, la incidencia que tiene en el cuerpo social; es decir, su vida social, el modo en que se construye socialmente, no es considerado de su incumbencia. Esto es un error a estas alturas de nuestra historia, cuando algo nuevo no elegido está emergiendo entre las ruinas de la crisis y la modernidad, algo que no es, por definición, superador de las limitaciones que ésta tenía.

Las posturas técnico-instrumentales deberían tomar nota de lo que sucede en distintos lugares del mundo (por ejemplo, Palmira), para comprender que los riesgos sociales vinculados a cómo el patrimonio es significado, apropiado o negado por distintos agentes sociales pueden suponer, en un momento dado, un riesgo para eso que tanto les preocupa: la conservación física del objeto patrimonial, por no hablar de las vidas humanas que también se ponen en riesgo. Catalogar como riesgo los "actos antisociales" (y no las dinámicas políticas y económicas que los generan, ya no digamos con el rol que el patrimonio puede desempeñar en estas dinámicas) es quedarse con el dedo que señala la luna (véase Téllez y Parga-Dans 2015 para un análisis detallado de los conflictos sociales en torno al bien).

Es cierto que sería pertinente, en el marco de nuestra propuesta, considerar el "riesgo de insostenibilidad por desaparición" (por ensayar una denominación) como un riesgo social, y no sólo como un riesgo para la conservación de la materialidad del bien, insistimos, ya que supone que las generaciones futuras no podrán disfrutar de él, como señalan con clarividencia algunos especialistas (Ontañón y Rodríguez, 2014:54). En este sentido, medidas como las adoptadas en Francia para la socialización de la cueva de Chauvet (http://archeologie.culture.fr/chauvet/es) parecen lo más sensato, pero las circunstancias concretas de esta cueva, descubierta en 1994, son totalmente diferentes a las de Altamira, 
como sugiere el propio Ontañón en Vicente (2015). Por otro lado, la excepcionalidad de un yacimiento como "la cueva de los sueños olvidados" puede justificar una inversión multimillonaria (aunque no exenta de controversia; por ejemplo, Jones 2015), pero no puede ser una medida estándar aplicable a cualquier otro sitio amenazado. En todo caso, la evaluación de este "riesgo de insostenibilidad por desaparición" no debería reducirse a un diagnóstico simplista ni a una medida conservadora sin matices, como hemos tratado de argumentar.

Nuestra investigación nos permitió plantear, de forma tentativa, algunas medidas destinadas a mitigar los problemas sociales asociados a los problemas de conservación y a propiciar, además, una socialización de Altamira más amplia y más profunda. Aunque no fueron recogidas en el Plan de Conservación Preventiva, estas propuestas se orientaban a dotar a Altamira de una nueva vida social más activa mediante variables cuyo seguimiento podría realizarse a través de diversas acciones. Además de algunas medidas más convencionales (basadas en sondeos y cuestionarios), nuestra propuesta incluía algunas estrategias alternativas (Barreiro 2015):

1. Estrategia de recuperación de vínculos en torno al sitio, integración de identidades y fomento de la participación: mediante grupos de discusión y/o talleres con agentes locales y regionales, diseñando una agenda colaborativa, habilitando un espacio en el Museo para propiciar la participación de la población local en el discurso expositivo a través de la memoria oral y la historia del sitio, alentando la participación de personal docente en las actividades didácticas, entre otras propuestas.

2. Estrategia de comunicación y transparencia para la revalorización de Altamira y el fomento de la conservación preventiva: entendiendo que no se trata sólo de concienciar y sensibilizar sobre la necesidad de proteger el patrimonio, sino de incorporar la fragilidad de Altamira como parte del discurso museográfico, asumiendo su especificidad, haciendo transparente la gestión técnica de la cueva y convirtiendo a los agentes sociales en agentes activos de la conservación o, parafraseando el lenguaje de la seguridad, en recursos preventivos.

3. Estrategia de reaproximación de los profesionales de la cultura y el arte a Altamira: propiciando un incremento de los vínculos entre Altamira y aquellos profesionales que se nutren, de una manera u otra, del poder estético, evocador y semántico del sitio, así como de su valor como medio de transmisión de conocimientos, valores y actitudes.

Estas propuestas permitirían abordar acciones de recuperación de vínculos y de comunicación social que giraban en torno a la identidad de Altamira como lugar, como evento de encuentro constante entre historias de vida, procesos sociales e identidades personales y grupales asociadas a la existencia de este espacio en época contemporánea, sin menoscabo de su condición de obra de arte prehistórica y de yacimiento arqueológico. 
La clave de este modo de orientar el futuro de los sitios patrimonio de la humanidad, como es el caso de Altamira, pero que también podría ser el de cualquier otro, empezando por Santiago de Compostela, es la necesidad de diseñar nuevos modos de patrimonialización que vayan más allá de la disyuntiva entre conservación y uso para propiciar un compromiso social. Esto convertiría el dilema del acceso físico a los bienes patrimoniales en una cuestión circunstancial o, en todo caso, en un asunto de responsabilidad socialmente compartida. Esto nos situaría en el escenario de la cuarta vida de los sitios patrimoniales, más rica y compleja que la presente.

Podemos acabar con una propuesta práctica y metodológica concretas. Dejemos de pensar que un sitio declarado World Heritage Site sigue siendo el mismo antes y después de la declaración; que sólo ha cambiado la cartelería o el aparcamiento. Empecemos a pensar que llegará a ser tan distinto como es lo que ahora vemos de lo que fue en el pasado. Y empecemos entonces a hacer auténticos estudios prospectivos que permitan modelizar escenarios de evolución de la vida del sitio para ver cómo resolvemos los problemas, y sin duda los conflictos, que surgirán.

Tendemos a pensar que los sitios puestos en valor siguen siendo el mismo sitio que eran antes, que simplemente representan una nueva fase. Pero no es cierto, son un sitio distinto, un sitio nuevo. Con la declaración y valorización del sitio, éste despierta a una vida nueva. Esa vida es, como toda vida, impredecible. Cuando aquí la llamamos vida, vamos más allá del uso metafórico del término. Queremos decir que tenemos que reconocer al sitio como una entidad viva, en constante transformación (al modo en que lo plantea, por ejemplo, Jullien 2010).
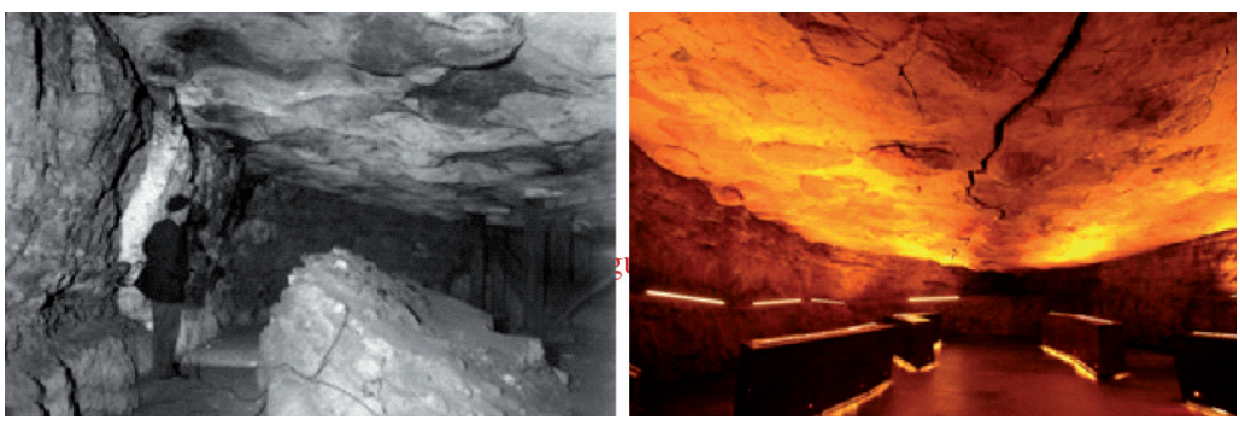

Figura 7. Una imagen del interior de la cueva en los años 50, junto a una imagen de la sala de polícromos de la neocueva. Fuentes: Museo de Altamira e Incipit.

La gestión (transmoderna) del patrimonio convierte los sitios en lugares de socialización. Reconocer este hecho es el punto de partida para poder realizar una prospectiva reflexiva acerca de las consecuencias que nuestras acciones ocasionarán en el futuro. Los lugares tienen una vida, pero no viven solos, viven a través de nosotros, se crean y recrean 
a través de nuestra acción. Hacia eso apunta el modelo de las cuatro vidas de los sitios que aquí planteamos: la vida 1.0 u "original”, la vida 2.0 o posdeposicional, "natural”, las vidas 3.1 y 3.2 o "patrimonializadas" (modernas), y la vida 4.0 o de plena incorporación a la vida social.

El gestor, tanto como el moderno que nunca lo fue (por juguetear aquí con el sentido del célebre axioma latouriano), tienden a decir siempre que estos planteos son demasiado teóricos, imposibles de llevar a la práctica. La propuesta que planteamos aquí lo contradice. Generalmente se concreta en principios de acción efectiva muy sencillos. Por ejemplo: el sitio tiene que incluir su propia historia dentro del dispositivo de valorización y presentación que lo ilustra; éste tiene que contar cómo era el sitio antes de este "sitio"; la historia que se cuenta allí debe incluir a las historias de la comunidad propietaria.

La socialización de un sitio patrimonial (sobre todo si es tan rico y complejo como Altamira) exige hacer no sólo una historia y una antropología del lugar, sino una auténtica arqueología (no sólo en sentido foucaultiano) de sus modos de patrimonialización. Los resultados de esta arqueología deberían ser parte de la narrativa, del sentido de lugar, de la vida social en torno al mismo. No hacerlo es desgajar el sitio de su tradición (como denuncian muchos de los visitantes a Altamira través de los libros de visitas, analizados en detalle por Ayán 2015), y mantener un rumbo cada vez más alejado de la misma, y más acorde con una lógica en la que la singularidad de los sitios se pliega ante las exigencias de mercantilización, estandarización y homogeneización propias del capitalismo tardío y global. ¿Es éste el futuro que queremos para nuestros sitios?

\section{AGRADECIMIENTOS}

Este texto no habría sido posible sin todas las personas que participaron, de una u otra manera, en el Proyecto Valor Social de Altamira. Para ellas es nuestro agradecimiento principal.

Tampoco queremos dejar pasar la oportunidad de agradecer a las personas que han revisado el manuscrito la pertinencia de sus comentarios, sugerencias y correcciones, que sinceramente creemos que han contribuido a mejorar el original. 


\section{BIBLIOGRAFÍA}

Altares, G. 2015. "Los científicos se rebelan contra la reapertura de Altamira". Noticia en El País 19-Marzo-2015: https://elpais.com/cultura/2015/03/18/actualidad/1426699070_744131.html

Augé, M. 1993. Los no lugares. Espacios del anonimato. Una antropología de la sobremodernidad. Barcelona: Gedisa.

Ayán X. 2015. Altamira vista por los españoles. Madrid: JAS Editorial.

Barreiro, D. 2015. Altamira, tercera vida. En Castillo, Alicia (Ed.). Actas del Segundo Congreso Internacional de Buenas Prácticas en Patrimonio Mundial: Personas y Comunidades, Menorca, 29 de abril - 2 de mayo de 2015. Madrid: Universidad Complutense: 63-80.

Barreiro, D. y Criado-Boado, F. 2015. Analizando el valor social de Altamira. Revista PH Instituto Andaluz del Patrimonio Histórico $n^{o}$ 87, abril 2015, pp. 108-127.

Barreiro, D. y Varela-Pousa, R. 2018. Hacia una gestión de riesgos crítica en patrimonio cultural. Comunicación presentada al III Congreso Internacional de Buenas Prácticas en Patrimonio Mundial. Acciones Integradas. Maó, Menorca, 2-5 de mayo de 2018.

Ayán, X.; Barreiro, D.; Criado-Boado, F.; Nicolau, A.; Parga-Dans, E.; Sánchez-Carretero, C.; Santos-Estévez, M. y Téllez, V. 2015. Comunicado del equipo del Proyecto Valor Social de Altamira sintetizando sus resultados en relación con el régimen de acceso a la cueva, 18/05/2015.

De Las Heras, C. 2003. El descubrimiento de la cueva de Altamira, En Redescubrir Altamira, Lasheras, J. A. (ed), Turner, Madrid: 17-27.

Departamento de Prehistoria de la Universidad Complutense de Madrid. 2014. Declaración sobre la conservación de las pinturas de la cueva de Altamira y el "programa de investigación” llevado a cabo por el Ministerio de Cultura de España, Madrid, 17/12/2014. Con la adhesión del Instituto de Historia del CSIC.

https://prehistoriaucm.files.wordpress.com/2015/03/conservacion-altamira-1.pdf

Departamento de Prehistoria de la Universidad Complutense de Madrid. 2016. Propuesta argumentada de cierre de la cueva de Altamira con vistas a su adecuada conservación, 25/02/2016.

https://prehistoriaucm.files.wordpress.com/2016/04/texto-departamento-prehistoria-2016.pdf

Fatás, P. 2011. Altamira, símbolo, identidad y marca. Simposio Internacional El patrimonio cultural como símbolo, Fundación del Patrimonio Histórico de Castilla y León: 161-186.

Funtowicz, S. y Ravetz, P. 2000. La ciencia posnormal. Ciencia con la gente. Barcelona: Icaria Editorial.

González-Ruibal, A; Alonso, P. and Criado-Boado F. 2017. Against reactionary populism: Towards a new Public Archaeology. Antiquity. Accepted and forthcoming. 
Grosfoguel, R. 2011. Decolonizing Post-Colonial Studies and Paradigms of Political Economy: Transmodernity, Decolonial Thinking and Global Coloniality, Transmodernity: Journal of Peripheral Cultural Production of the Luso-Hispanic World Vol. 1, No. 1., 2011

Gustaffson, A. and Karlsson, H. 2014, Authenticity in Practice. A comparative discussion of the authenticity, staging and public communication ta eight World Heritage classified rock art sites, Bricoleur Press, Lindome.

Hochadel, O. 2013. El mito de Atapuerca. Orígenes, ciencia, divulgación. Barcelona: Edicions UAB.

ICCROM and Canadian Conservation Institute. 2016. A Guide to Risk Management of Cultural Heritage

ICOMOS. 1994. Declaración de Nara sobre la autenticidad. http://www.icomoscr.org/doc/teoria/DOC.1994.nara.documento.sobre.autenticidad.pdf

ICOMOS. 2007. Carta de Ename para la Interpretación y Presentación de Sitios de Patrimonio Cultural.

http://www.enamecharter.org/downloads/ICOMOS_Carta_Interpretacion_ES.pdf

Jones, J. 2015. "Don't fall for a fake: the Chauvet cave art replica is nonsense", en The Guardian (International Edition), 15/04/2015.

https://www.theguardian.com/artanddesign/jonathanjonesblog/2015/apr/15/chauvet-cave-art-replica-is-nonsense

Jullien, F. 2010. Las transformaciones silenciosas. Barcelona: Bellaterra.

Junyent, E. 2016. Recensión de Ayán Vila, X. (2015). Altamira vista por los españoles. JAS Arqueología Editorial, Madrid, Revista d'Arqueologia de Ponent, 26: 355-363.

Lasheras, J. A (Ed.) 2003. Redescubrir Altamira, ed. Lasheras, J. A. Turner, Madrid

Lasheras, J. A. 2003. El arte paleolítico de Altamira, En Redescubrir Altamira, Lasheras, J. A. (ed) Turner, Madrid: 65-91.

Lasheras, J. A. 2004. La reproducción facsímil de Altamira. Litoral atlántico 4. Restaurar y reproducir: 3 .

Lasheras, J. A. 2006. La neocueva: un espacio singular del Museo de Altamira. Museos, espazo e discurso, IX Coloquio galego de museos, Lugo 26,27, 28 de outubro de 2006, Lugo: Museo Provincial, Deputación de Lugo: 203-213.

Low, S. 2014. Spatializing Culture. An Engaged Anthropological Approach to Space and Place. In Giesking, J. J. and Mangold, W. (Eds) The People, Place, and Space Reader. New York: Routledge: 34-38.

Lowenthal, D. 1998. The Heritage Crusade and the Spoils of History. Cambridge: Cambridge University Press.

Massey, D. 2005. For space. London, Thousand Oaks, New Delhi: SAGE.

Ministerio de Cultura y Deporte. 2017. "El Ministerio invertirá 4,5 millones de euros en el Museo de Altamira en la presente legislatura". Nota de prensa, 06/06/2017. https://www.mecd.gob.es/prensa-mecd/actualidad/2017/06/20170606-altamira. html 
Moro, Ó. 2009, Art Caves as Symbolic Spaces: the Case of Altamira, En Sites of memory: between scientific research and collective representations, Proceedings of the AREA seminar at Prague Castle, February 2006 Maříková-Kubková, J.; Schlanger, N.; Lévin, S. (Eds.)-Archeolosgicky ústav Akademie ved Ceske Republiky, Praha, pp. 69-77.

Múzquiz, M. y Saura, P. 2003. El facsímil del techo de los bisontes de Altamira. En Redescubrir Altamira, Lasheras, J. A. (ed). Madrid, Turner: 219-241.

NEARCH 2017. Archaeology and Heritage Management at World Heritage Sites, Social and Economic Involvements, International Conference. Berlín (Alemania), 16-18 de Octubre de 2017

Ontañón, R. y Rodriguez, J. A. 2014. Cave of Altamira and palaeolithic cave art of northern Spain. Composition, characteristics and management, Cuadernos de Arte Rupestre, 7: 37-57.

https://www.researchgate.net/publication/312174369_Cave_of_Altamira_and_palaeolithic_cave_art_of_northern_Spain_Composition_characteristics_and_management

Parga-Dans, E. and Alonso P. 2017. The Altamira controversy: Assessing the economic impact of a world heritage site for planning and tourism management, Journal of Cultural Heritage https://doi.org/10.1016/j.culher.2017.09.007

Pastor, A. 2016. Towards a Social Archaeological Conservation in Barcelona. Complutum Vol. 27 (2): 259-280.

Pastor, A. y Canseco, O. 2016. Hacia la autosostenibilidad en procesos de excavación: conservación preventiva y gestión de riesgos. Otarq Vol. 1 2016: 195-221.

Programa Altamira 2014a. Programa de Investigación para la conservación preventiva y régimen de acceso de la cueva de Altamira (2012-2014), Volumen I: Informe Final, Ministerio de Educación, Cultura y Deporte, Madrid.

Programa Altamira 2014b. Programa de Investigación para la conservación preventiva y régimen de acceso de la cueva de Altamira (2012-2014), Volumen II: Historia de la conservación de la cueva de Altamira (1868-2012), Ministerio de Educación, Cultura y Deporte, Madrid.

Programa Altamira 2014c. Programa de Investigación para la conservación preventiva y régimen de acceso de la cueva de Altamira (2012-2014), Volumen IV: Plan de Conservación Preventiva de la Cueva de Altamira, Ministerio de Educación, Cultura y Deporte, Madrid.

RTVE. 1955. Noticiario N 659 A. 25 de agosto de 1955. http://www.rtve.es/filmoteca/ no-do/not-659/1483023/

RTVE. 1964. Noticiario N 1138 B. 26 de octubre de 1964. http://www.rtve.es/filmoteca/ no-do/not-1138/1475866/

Saiz-Jimenez, C.; Cuezva, S.; Jurado, V.; Fernandez-Cortes, A.; Porca, E.; Benavente, D.; Cañaveras, J.; Sanchez-Moral, S. 2011. Paleolithic art in peril: policy and science collide at Altamira Cave. Science Vol. 334, Número 6052: 42-43. 
Saiz-Jimenez (Ed.). 2014. The Conservation of Subterranean Cultural Heritage. Leiden: CRC Press.

Téllez, V., y Parga-Dans, E. 2015. Altamira: hegemonía de élite y valor social en conflicto. In Actas del Segundo Congreso Internacional de Buenas Prácticas en Patrimonio Mundial: Personas y Comunidades, 29-30 de abril, 1 y 2 de mayo de 2015. Madrid, Universidad Complutense: 355-374.

Vicente, A. 2015. “Chauvet: neocueva sí, acceso al original, no”, en El País, 18/04/2015. 